\title{
The Detection of Tear Biomarkers for Future Prostate Cancer Diagnosis
}

\author{
Yong $\mathrm{Li}^{*}$,a,b \\ ${ }^{a}$ Cancer Care Centre, St George Hospital, Gray St, Kogarah, NSW 2217, Australia; ${ }^{b}$ St George Clinical School, Faculty \\ of Medicine, University of New South Wales, Kensington, NSW 2086, Australia
}

\begin{abstract}
Prostate cancer (CaP) continues to be the second leading cause of cancer-specific death in men in Western countries. The marker currently used for CaP detection is an increase in serum prostate specific antigen (PSA). However, the PSA test may give false positive or negative information and does not allow the differentiation of benign prostate hyperplasia (BPH), non-aggressive $\mathrm{CaP}$ and aggressive $\mathrm{CaP}$. Tears are a unique source of body fluid and contain proteins, peptides, mucins and lipids, which is useful for studying clinical proteomics. Advances in the field of proteomics have greatly enhanced the study of tears, with a greater number of proteins now being identified in tears. Identification of novel biomarkers in tear is a new area of development. Modern advances in the field of proteomic techniques hold the promise of providing the clinical oncologists with new tools to find novel $\mathrm{CaP}$ biomarkers for early diagnosis and prognosis.
\end{abstract}

Keywords: Prostate cancer, tear, biomarker, proteomics, diagnosis.

\section{INTRODUCTION}

Prostate cancer $(\mathrm{CaP})$ is the most common malignancy and is the second leading cause of cancer death in males [1]. In 2009 alone, it was estimated that $\mathrm{CaP}$ would be diagnosed in 192,000 men, and 27,300 would die of the disease in the United State [2]. The marker currently used for $\mathrm{CaP}$ detection is an increase in serum prostate specific antigen (PSA) [3]. However, the PSA test may give false positive or negative information and does not allow the differentiation of benign prostate hyperplasia (BPH), non-aggressive $\mathrm{CaP}$ and aggressive $\mathrm{CaP}$ [3]. The classical value of a PSA cut-off, 4.0 $\mathrm{ng} / \mathrm{mL}$, misses more than $75 \%$ and a PSA cut-off of 2.0 $\mathrm{ng} / \mathrm{mL}$ would miss more than $45 \%$ of biopsy detectable cancers [4]. Using PSA ranges below $3.0 \mathrm{ng} / \mathrm{mL}$ entails a very high risk of overdiagnosis and overtreatment as well as unnecessary biopsies [4]. These observations have also been confirmed by a recent report that found that serum PSA was related to the volume of the prostate; however, with population-based screening, it has become more inaccurate as a marker of cancer and may only relate to BPH $[5,6]$. Furthermore, there are emerging data from the Prostate Cancer Prevention Trial and other sources showing that a significant number of men with PSA scores $<4 \mathrm{ng} / \mathrm{mL}$ may have undetected $\mathrm{CaP}$ [7] while as many as $75 \%$ of men who have a positive PSA test (> $4.0 \mathrm{ng} / \mathrm{mL})$ do not have $\mathrm{CaP}$ [8]. Such reports imply that no single marker will accurately reflect the complex phenotypic changes associated with the development of cancer. Clearly, there is an urgent need for novel biomarkers or protein profiles in body fluids of CaP subjects to improve the early detection and accuracy of diagnosis, determine the aggressiveness of $\mathrm{CaP}$ and monitor the efficacy of treatment.

\footnotetext{
*Address correspondence to this author at the Cancer Care Centre, St George Hospital, Gray St, Kogarah, NSW 2217, Australia; Tel: +61-2-91132514; Fax: +61-2-9113-2514; E-mail: y.li@unsw.edu.au
}

\section{TEARS AS A SOURCE FOR BIOMARKERS}

Tears are a unique source of body fluid and contain mucins, glycoproteins, unglycosylated proteins, peptides, and lipids [9]. The major tear proteins are lysozyme, lactoferrin, secretory immunoglobulin A ( $\operatorname{sg}$ A), lipocalin, and lipophilin. The diverse composition of the tear fluid may be associated with variations in response to pathophysiological conditions which affect other areas of the organism, making the tear fluid useful for biomarker research. The change of protein components of tears has been reported in some local eye diseases $[10,11]$, systemic diseases such as diabetes [12] and cancers $[13,14]$. The tear proteome has been proposed to contain around 500 proteins [15], whereas that of se$\mathrm{rum} /$ plasma is estimated containing up to 10,000 proteins [16]. A much lower range of proteins and proportion of serum albumin and immunoglobulins in tears compared to serum makes proteomic analysis more straightforward. Proteomic analysis of tears has been carried out in our laboratories $[13,14,17]$. These results offer the potential for cancer diagnosis by analysing tear fluid proteins.

The collection of tears is relatively safe (e.g. no puncture), non-invasive, inexpensive, and the tears may be collected repeatedly with minimal discomfort to the patients. There is increasing interest in using tears to diagnose systemic diseases because of its simplicity in collection. In addition, tear contains constituents that are frequently altered in the presence of systemic diseases such as cancers, thereby rendering tears as a very desirable source for cancer diagnosis and monitoring.

However, there are still some challenges using tears as source for biomarker identification. Firstly, analysis of tear fluid samples for protein biomarker discovery is complicated by the differences in composition associated with these different collection methods, highlighting the requirement of a standard collection protocol for biomarker research. Another challenge is the requirement of highly sensitive and reliable techniques for analysis of the small amounts of tears able to 
be collected to ensure reproducible and quantifiable results. With the development of very sensitive proteomic techniques such as various mass spectrometries that require only 1-5 microlitres of tear, tears will be considered as a useful source of biomarkers for various diseases.

\section{TEAR BIOMARKERS IN CANCER RESEARCH}

Using two-dimensional gel electrophoresis (2DGE) technique, our research team found that lacryglobin (mammaglobin, a low molecular weight protein) could be detected in a breast cancer patient with bone metastasis but not in healthy controls, suggesting that lacryglobin in human tears may be a potential marker for breast cancer [13]. Later on, mammaglobin was further confirmed to be a potential marker for metastasis of breast cancer cells to lymph nodes [18].

The surface-enhanced laser desorption/ionization timeof-flight mass spectrometry (SELDI-TOF-MS) ProteinChip has been introduced [19] as an alternative to 2DGE. This technology utilizes affinity surfaces to retain proteins based on their physical or chemical characteristics, and is followed by direct analysis using TOF-MS. It is a rapid and reproducible technique to generate protein expression profiles known as "phenomic fingerprints". Furthermore, SELDITOF-MS is more sensitive and requires only small amounts of sample (2-3 $\mu \mathrm{L})$ compared to $2 \mathrm{DGE}$. This system has enabled detection of critical proteins directly from crude mixtures without labour intensive pre-processing and has been proven to be a very useful tool for identifying biomarkers in various cancers as well as other diseases.

Lebrecht et al. (2009) recently demonstrated a biomarker panel from tear fluids successfully generated by SELDITOF-MS allows breast cancer patients to be differentiated from healthy women [20]. The same groups further confirmed that the diagnostic pattern differentiated cancer patients from controls with a specificity and sensitivity of approximately $90 \%$ in tear fluid using the same technique [21]. These results indicate that tears may be a potential source of biomarkers for breast cancer. We have analyzed pooled tear proteins from $\mathrm{CaP}$ patients $(n=8)$ and normal controls $(n=3)$ using SELDI-TOF-MS. A reversed-phase surface protein chip (H50) was used to analyze the samples. Our results indicate that there are two peptides missing (7110 and 14213 $\mathrm{Da})$ in the tears from $\mathrm{CaP}$ patients compared with normal, and have shown the potential of proteomic analysis of tears as a possible new way for finding novel $\mathrm{CaP}$ biomarkers by SELDI-TOF [14].

However, whilst this approach has been used in multiple studies, the major disadvantage is that significant further work is necessary to identify and verify biomarker proteins that are detected in the peptide fingerprint.

\section{KEY PROTEOMIC TECHNOLOGIES FOR FUTURE TEAR BIOMARKER RESEARCH}

Proteomic studies are the emerging era for searching biomarkers. Key elements of proteomic studies are the ability of separating thousands of peptide/proteins simultaneously, comparing protein profiles from different samples and indentifying proteins. Several technologies are important for this study and they include gel based technologies and nongel based technologies (Mass spectrometry-MS).
Two-Dimensional Differential in-Gel Electrophoresis (2D-DIGE)

2D-DIGE is a gel-based and fairly recent improvement of the 2DGE technology using fluorescent molecules (CyDyes), or fluors, that are used to pre-label samples prior to separation by 2DGE. The internal standard is a pool of all samples used in the experiment and is used not only to normalize the Cy3- and Cy5-labeled samples, but also to compare across the other 2D gels in the experiment. This significantly reduces the intergel variability that plagues other 2D gel-based analyses. CyDyes also show a linear response to protein concentration up to 5 orders of magnitude [22]. The gel is scanned at different emission wavelengths and multiple images corresponding to the different samples are generated. This methodology significantly improves sample throughput and greatly enhances gel reproducibility [23]. Our preliminary results indicate that the $2 \mathrm{D}$-DIGE technique is promising for $\mathrm{CaP}$ tear biomarker identification in the future.

\section{Isobaric Tags for Relative and Absolute Quantitation (iTRAQ)}

Due to better sensitivity and reproducibility over 2D-bsed methods [24], mass spectrometry (MS)-based technology is one of the most powerful tools in analyzing proteome. iTRAQ is a shot-gun based technique developed by Darryl Pappin and colleagues at Applied Biosystems in 2004 [25] which allows the concurrent identification and relative quantification of hundreds of proteins in up to 8 different biological samples in a single experiment $[25,26]$. This unique approach labels samples with 8 independent reagents of the same mass that, upon fragmentation in MS/MS, give rise to 8 unique reporter ions $(\mathrm{m} / \mathrm{z}=113-121)$ that are subsequently used to quantify the 8 different samples, respectively. MS/MS fragmentation, in addition to giving strong reporter ion signals, also yields strong signature $y$ - and b- ions without changing the charge state of any given peptide to allow for more confident protein identification simultaneously with the quantification. iTRAQ based quantitative proteomics is a promising approach for global comparison of protein expression in relatively small amounts of samples such as tear. The iTRAQ technology has many advantages over other proteomic techniques:

- $\quad$ ITRAQ reagents allow parallel proteomic analysis of 8 different samples under the same experimental conditions, resulting in reduced systematic error and increased electrospray ionization efficiency leading to higher sensitivity; reducing the analysis time.

- $\quad$ Protein sequence coverage obtained using iTRAQ reagents is similar to that obtained using other shotgun proteomic approaches.

- $\quad$ iTRAQ reagents can be used to identify and quantify proteins across diverse molecular weight (MW) and pI ranges, functional categories, cellular locations and abundances.

- $\quad$ The multiplexing capacity of these reagents allows information replication within certain liquid chromatography/ mass spectrometry (LC-MS/MS) experimental regimes, providing additional statistical validation within any given experiment. iTRAQ is relatively high throughput due to sample multiplexing. 
- Because protein identification and quantification is based on tandem mass spectrometric (MS/MS) evidence, increased selectivity, specificity, and confirmatory power are achieved [25].

$\mathrm{Wu}$ et al. compared 2DDIGE, identified by isotopecoded affinity tag (ICAT), and iTRAQ to show that iTRAQ is the most sensitive proteomics quantitation method among the three techniques evaluated, based on the number of detected peptides [27]. iTRAQ was observed to provide a more consistent quantitation in comparison with $2 \mathrm{DGE}$ for proteins stained with lower intensity on 2DE gels [28]. Zhou et al. (2009) used iTRAQ technology to identify 10 potential tear protein biomarkers for dry eye syndrome: $\alpha$-enolase, $\alpha$ 1-acid glycoprotein1, S100A8 (caligranulin A), S100A9 (calgranulin B), S100 A4, S100 A11 (calgizzarin), prolactininducible protein (PIP), lipocalin-1, lactoferrin and lyzozyme. In particular, $\alpha$-enolase and S100 A4 were successfully verified by enzyme-linked immunosorbent assay (ELISA) [29]. This technique is promising for future $\mathrm{CaP}$ tear proteomic studies.

\section{Multiple Reaction Monitoring (MRM)}

MRM-MS has emerged as an alternative and a highly specific, sensitive technology to immunoassays for quantification of target proteins or peptides. It offers superior multiplexing capabilities, allowing for the simultaneous quantification of numerous proteins in parallel. MRM achieves high analytical specificity and sensitivity by selecting predetermined precursor molecular ions for collisioninduced dissociation and monitoring the appearance of several diagnostic product ions. When identified in combination, the precursor and product ions confirm the presence of the analyte of interest. Importantly, addition of isotopically labeled internal standards allows absolute quantification. Numerous precursor ions can be monitored in 1 experiment, particularly when using scheduled MRMs, which incorporate prior knowledge of peptide elution times into the LC-MS/MS program [30, 31]. Recently, a large National Cancer Institute-sponsored interlaboratory study showed that an MRM approach can quantify target proteins in a background of unfractionated human plasma with highly robust and reproducible results, supporting the notion that this technology is suitable for biomarker discovery [32].

Under MRM, the mass spectrometer is set up to monitor only specific mass/charge $(\mathrm{m} / \mathrm{z})$ values of interest; as a consequence, the probability of detecting even low levels of a peptide in the presence of a complex mixture of peptides is much higher. MRM has been the method of choice for quantification of low levels of small molecules, including drugs or metabolites, as well as peptides $[30,33]$. Since a specific antibody does not need to be developed for MRM, this technique can be quickly used to verify candidate biomarkers and shorten the advance to validation stages using MRM or ELISA. An attribute of MRM is its multiplexing capability for many target proteins per run; antibody-based assays measure a limited number of proteins simultaneously. MRM would be the inevitable choice for biomarker verification when there is no appropriate antibody. Use of MRM in biomarker development also can enhance the measure of posttranslation modifications (PTMs), which are difficult tasks for antibody-based system [34-36].
Using sequential dyes to analyze phospho-, glyco- and total tear protein profiles (Pro-Q Diamond for phosphoprotein, Pro-Q Emerald for glycoprotein and Sypro Ruby for total protein in $2 \mathrm{DGE}$, our research team have recently identifies a novel tear protein, dermcidin [37]. The identified dermcidin was further validated by MRM. This study provides the groundwork for understanding the PTM of tear proteins and consequently these methods could be useful in the search for $\mathrm{CaP}$ biomarkers in tears. Studies of several potential tear biomarkers in $\mathrm{CaP}$ patients, $\mathrm{BPH}$ patients and control subjects by MRM are currently being investigated in our laboratory.

\section{CONCLUSIONS}

Proteomic techniques are modern and emerging technologies used to study proteins in biological samples. The techniques can separate, simultaneously, thousands of proteins in samples and the proteins can be sequentially identified. Tear is a unique source of body fluid and contains proteins and peptides, and can be collected as a non-invasive procedure. Identification of novel biomarkers in tear is a new area of development. Identification of tear proteins may lead to the discovery of novel biomarkers for cancer diagnosis or monitoring cancer progression. The biomarkers could be useful to determine whether a patient's cancer is surgically curable and predict the future clinical course of $\mathrm{CaP}$ and/or the response to future chemotherapy.

\section{ACKNOWLEDGEMENTS}

I appreciate our team members who are working on the prostate cancer tear project including Ms Jingjing You (Faculty of Medicine, UNSW, Sydney Australia), Prof Mark Willcox (School of Optometry and Vision Science, UNSW, Sydney, Australia), Dr Paul Cozzi (St George Hospital, Sudney, Australia), Dr Brad Walsh (Minomic International Ltd, Sydney, Australia), Prof Pamela Russell (Australian Prostate Cancer Research Centre-Queensland, Institute of Health and Biomedical Innovation, Queensland University of Technology, Australia) and Dr Zhenjun Zhao (Brien Holden Vision Institute, Sydney, Australia). Our study was supported by funds from the Australian Research Council (ARC)-linkage grant, a Career Development Fellowship from Cancer Institute NSW, Australia (YL) and a Career Development Fellowship from National Health Medical Research Council (NHMRC), Australia (YL).

\section{ABBREVIATIONS}

\begin{tabular}{|c|c|}
\hline $\mathrm{BPH}$ & $=$ Benign prostate hyperplasia \\
\hline $\mathrm{CaP}$ & $=$ Prostate cancer \\
\hline 2D-DIGE & $\begin{aligned}= & \text { Two-dimensional differential in-gel } \\
& \text { electrophoresis }\end{aligned}$ \\
\hline 2DGE & $=$ Two-dimensional gel electrophoresis \\
\hline ELISA & $=$ Enzyme-linked immunosorbent assay \\
\hline ICAT & $=$ Isotope-coded affinity tag \\
\hline iTRAQ & $\begin{array}{l}=\text { Isobaric tags for relative and absolute } \\
\text { quantitation }\end{array}$ \\
\hline LC-MS/MS & 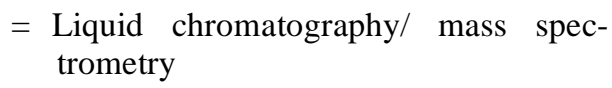 \\
\hline $\mathrm{R}$ & Multiple reaction monitoring \\
\hline
\end{tabular}




$\begin{array}{ll}\text { MS } & =\text { Mass spectrometry } \\ \text { MW } & \text { Molecular weight } \\ \text { PSA } & \text { Prostate specific antigen } \\ \text { PTM } & \text { Post-translation modification } \\ \text { SELDI-TOF-MS }= & \begin{array}{l}\text { Surface-enhanced laser desorp- } \\ \text { tion/ionization time-of-flight mass } \\ \end{array} \\ & \text { spectrometry }\end{array}$

\section{REFERENCES}

[1] Weir HK, Thun MJ, Hankey BF, et al. Annual Report to the Nation on the Status of Cancer, 1975-2000, featuring the uses of surveillance data for cancer prevention and control. J Natl Cancer Inst 2003; 95: 1276-99.

[2] Jemal A, Siegel R, Ward E, Hao Y, Xu J, Thun MJ. Cancer statistics, 2009. CA Cancer J Clin 2009; 59: 225-49.

[3] Smith RA, Cokkinides V, Eyre HJ. American Cancer Society guidelines for the early detection of cancer, 2003. CA Cancer J Clin 2003; 53: 27-43.

[4] Schroder FH, Carter HB, Wolters T, et al. Early detection of prostate cancer in 2007. Part 1: PSA and PSA kinetics. Eur Urol 2008; 53: 468-77.

[5] Stamey TA, Caldwell M, McNeal JE, et al. The prostate specific antigen era in the United States is over for prostate cancer: what happened in the last 20 years? J Urol 2004; 172: 1297-301.

[6] Schroder FH, Roobol MJ, Andriole GL, et al. Defining increased future risk for prostate cancer: evidence from a population based screening cohort. J Urol 2009; 181: 69-74.

[7] Thompson IM, Goodman PJ, Tangen CM, et al. The influence of finasteride on the development of prostate cancer. N Engl J Med 2003; 349: 215-24.

[8] Thompson IM, Pauler DK, Goodman PJ, et al. Prevalence of prostate cancer among men with a prostate-specific antigen level < or =4.0 ng per millilitre. N Engl J Med 2004; 350: 2239-46.

[9] Van Haeringen NJ. Clinical biochemistry of tears. Surv Ophthalmol 1981; 26: 84-96.

[10] Grus FH, Sabuncuo P, Augustin AJ. Analysis of tear protein patterns of dry-eye patients using fluorescent staining dyes and twodimensional quantification algorithms. Electrophoresis 2001; 22: 1845-50.

[11] Tiffany JM. Tears in health and disease. Eye 2003; 17: 923-6.

[12] Herber S, Grus FH, Sabuncuo P, Augustin AJ. Two-dimensional analysis of tear protein patterns of diabetic patients. Electrophoresis 2001; 22: 1838-44.

[13] Evans V, Vockler C, Friedlander M, et al. Lacryglobin in human tears, a potential marker for cancer. Cli Exp Ophthalmol 2001; 29: 161-3.

[14] Li Y, Cozzi PJ, Zhao J, Walsh BJ, Russell PJ, Willcox M. Identification of novel biomarkers in tears for prostate cancer diagnosis and prognosis. Advances in Proteomics in Cancer Res, AACR Amelia Island, Florida 9. 2007

[15] de Souza GA, Godoy LM, Mann M. Identification of 491 proteins in the tear fluid proteome reveals a large number of proteases and protease inhibitors. Genome Biol 2006; 7: R72.

[16] Wrotnowski, C. The future of plasma proteins - Compounds represent both greatest good and worst danger. Genet Eng News 1998; 18: 14.

[17] Glasson MJ, Molloy MP, Walsh BJ, Willcox MDP, Morris CA, Williams KL. Development of mini-gel technology in twodimensional electrophoresis for mass-screening of samples: application to tears. Electrophoresis 1998; 19: 852-5.
[18] Ouellette RJ, Richard D, Maicas E. RT-PCR for mammaglobin genes, MGB1 and MGB2, identifies breast cancer micrometastases in sentinel lymph nodes. Am J Clin Pathol 2004; 121: 637-43.

[19] Hutchens T, Yip T. New desorption strategies for the mass spectrometric analysis of macromolecules. Rapid Commun Mass Spectrom 1993; 7: 576-80.

[20] Lebrecht A, Boehm D, Schmidt M, Koelbl H, Schwirz RL, Grus FH. Diagnosis of breast cancer by tear proteomic pattern. Cancer Genomics Proteomics 2009; 6: 177-82.

[21] Lebrecht A, Boehm D, Schmidt M, Koelbl H, Grus FH. Surfaceenhanced Laser Desorption/Ionisation Time-of-flight Mass Spectrometry to Detect Breast Cancer Markers in Tears and Serum. Cancer Genomics Proteomics 2009; 6: 75-83.

[22] Lilley KS, Friedman DB. All about DIGE: quantification technology for differential-display 2D-gel proteomics. Expert Rev Proteomics 2004; 1: 401-9.

[23] Issaq HJ, Veenstra TD. The role of electrophoresis in disease biomarker discovery. Electrophoresis 2007; 28: 1980-8.

[24] Aebersold R, Mann M. Mass spectrometry-based proteomics. Nature 2003; 422: 198-207.

[25] Ross PL, Huang YN, Marchese JN, et al. Multiplexed protein quantitation in Saccharomyces cerevisiae using amine-reactive isobaric tagging reagents. Mol Cell Proteomics 2004; 3: 1154-6.

[26] Pierce A, Unwin RD, Evans CA, et al. Eight-channel iTRAQ enables comparison of the activity of six leukemogenic tyrosine kinases. Mol Cell Proteomics 2008; 7: 853-63.

[27] Wu WW, Wang G, Baek SJ, Shen RF. Comparative study of three proteomic quantitative methods, DIGE, cICAT, and iTRAQ, using 2D gel- or LC-MALDI TOF/TOF. J Proteome Res 2006; 5: 651-8.

[28] Aggarwal K, Choe, LH, Lee KH. Shotgun proteomics using the iTRAQ Isobaric tags. Brief Funct Genomic Proteomic 2006; 5: 112-20.

[29] Zhou L, Beuerman RW, Chan CM, et al. Identification of tear fluid biomarkers in dry eye syndrome using iTRAQ quantitative proteomics. J Proteome Res 2009; 8: 4889-905.

[30] Anderson L, Hunter CL. Quantitative mass spectrometric multiple reaction monitoring assays for major plasma proteins. Mol Cell Proteomics 2006; 5: 573-88.

[31] Stahl-Zeng J, Lange V, Ossola R, et al. High sensitivity detection of plasma proteins by multiple reaction monitoring of N-glycosites. Mol Cell Proteomics 2007; 6: 1809-17.

[32] Addona TA, Abbatiello SE, Schilling B, et al. Multi-site assessment of the precision and reproducibility of multiple reaction monitoring-based measurements of proteins in plasma. Nat Biotechnol 2009; 27: 633-41.

[33] Luna LG, Williams TL, Pirkle JL, Barr JR. Ultra performance liquid chromatography isotope dilution tandem mass spectrometry for the absolute quantification of proteins and peptides. Anal Chem 2008; 80: 2688-93.

[34] Unwin RD, Griffiths JR, Leverentz MK, Grallert A, Hagan IM, Whetton AD. Multiple reaction monitoring to identify sites of protein phosphorylation with high sensitivity. Mol Cell Proteomics 2005; 4: 1134-44.

[35] Mayya V, Rezual K, Wu L, Fong MB, Han DK. Absolute quantification of multisite phosphorylation by selective reaction monitoring mass spectrometry: determination of inhibitory phosphorylation status of cyclin-dependent kinases. Mol Cell Proteomics 2006; 5: 1146-57.

[36] Hulsmeier AJ, Paesold-Burda P, Hennet T. N-glycosylation site occupancy in serum glycoproteins using multiple reaction monitoring liquid chromatography-mass spectrometry. Mol Cell Proteomics 2007; 6: 2132-8

[37] You J, Fitzgerald A, Cozzi PJ, et al. Post-translation modification of proteins in the tear. Electrophoresis 2010; 31: 1853-61.

(C) Yong Li; Licensee Bentham Open.

This is an open access article licensed under the terms of the Creative Commons Attribution Non-Commercial License (http://creativecommons.org/licenses/by-nc/3.0/) which permits unrestricted, non-commercial use, distribution and reproduction in any medium, provided the work is properly cited. 